Running Head: IMAGINTION AND SOCIAL COGNITION IN CHILDHOOD

\title{
Imagination and Social Cognition in Childhood
}

\author{
Tamar Kushnir \\ Department of Psychology and Neuroscience, Duke University
}

\begin{abstract}
Author Note
Correspondence concerning this article should be addressed to Tamar Kushnir, Department of Psychology and Neuroscience, Duke University, 417417 Chapel Drive, Box 90086, Durham, NC 27708, email: tamar.kushnir@duke.edu. Sincerest thanks to my academic village, especially Marianella Casasola, Melissa Koenig, Shaun Nichols, Mark Sabbagh, Dave Sobel, and Jessica Sommerville for stimulating discussions and ideas, and additionally to John McKain, Scott Partington, Yeonju Suh and Meltem Yucel for comments on earlier versions of the manuscript. The author declares that they had no conflicts of interest with respect to their authorship or the publication of this article.
\end{abstract}

Funding Information

The writing of this paper was supported by NSF BCS-1823658, NSF SL- 1955280 and USDA Hatch NYC-321434 awards to T.K. 


\begin{abstract}
Imagination is a cognitive process used to generate new ideas from old, not just in the service of creativity and fantasy, but also in our ordinary thoughts about alternatives to current reality. In this paper I argue for the central function of imagination in the development of social cognition in infancy and childhood. In section 1 I review a work showing that even in the first year of life, social cognition can be viewed through a nascent ability to imagine the physical possibilities and physical limits on action. In section 2, I discuss how imagination of what should happen is appropriately constrained by what can happen, and how this influences children's moral evaluations. In the final section, I suggest developmental changes in imagination - especially the ability to imagine improbable events - may have implications for social inference, leading children to learn that inner motives can conflict. These examples point to a flexible and domain-general process that operates on knowledge to make social meaning.
\end{abstract}

Keywords: Social cognition, causal learning, cognitive development, imagination, modal cognition, moral development, theory of mind

Graphical Abstract Caption: Children's social cognitive development depends on general and increasingly flexible ability to imagine alternative possibilities for action. 
Imagination and Social Cognition in Childhood

Imagination makes new things out of old parts. It is an act of generating, from bits of old knowledge, new ideas, and new possibilities. We imagine forward in time, seeing some possible paths ahead, and that foresight allows us to predict, plan, and decide (Gilbert \& Wilson, 2007; Lagattuta, 2005; Seligman et al., 2013; Suddendorf, 2010). We imagine backwards in time, creating stories to explain how and why we got to where we are (Addis, 2020; De Brigard et al., 2019; Roediger lii \& Marsh, 2003). Likewise, this ability to imagine allows us to make sense of the world around us. Explaining how things happen invokes hypothetical and counterfactual imaginings about what can or could happen otherwise (Gerstenberg et al., 2021; Hitchcock, 2001; Walker \& Gopnik, 2013; Woodward \& Hitchcock, 2003). Importantly, imagination is not a specialized skill only possessed by certain types of "imaginative" or "creative" people. It describes a general cognitive process we all use to generate simulations that go beyond immediately available sensory input.

The developmental origins of our imaginative capacities can be seen in the pretend play of toddlers (Harris, 2000; Piaget, 1952) and the counterfactual reasoning (Harris et al., 1996; Nyhout \& Ganea, 2019a; Sobel, 2004) and future-thinking (Atance, 2015; Redshaw et al., 2019) abilities of preschool and school-age children. A large body of work suggests that a nascent ability to simulate alternatives to current reality emerges alongside and in relation to children's developing knowledge of the world. For example, 3- to 5-year-old children can come to appropriate conclusions about alternatives to a sequence of past events, a form of counterfactual reasoning (Harris et al., 1996; Nyhout \& Ganea, 2019b). Similarly, children can use knowledge of the past to predict the future and can make decisions based on planning for future needs (Atance et al., 2017; Burns, McCormack, et al., 2021; McCormack et al., 2019; Suddendorf et al., 2011). Children's earliest imaginative play is tied to their emerging understanding of real events (Harris, 2021; Weisberg \& Gopnik, 2013). At times children's simulations look different from those of adults (Beck \& Riggs, 2014; Rafetseder \& Perner, 2014) yet research shows that differences are systematically related to children's emerging conceptual knowledge, not to an inability to simulate alternatives to reality (Kominsky et al., 2021; Nyhout \& Ganea, 2019a). In fact, teaching children to explicitly simulate alternatives when reasoning seems to be more of a matter of prompting or 
encouragement, rather than explicit tuition (Engle \& Walker, 2021; Walker \& Nyhout, 2020). Together these findings suggests that our ability to imagine alternatives to reality is as central to cognition as our ability to reason and learn.

In this paper, I draw on this work to offer a perspective on the development of social cognition in infancy and early childhood. Social cognition is defined as all the ordinary ways in which we make sense of the behavior of people. "People" includes individuals to whom we are closely connected and whose idiosyncrasies we learn about first-hand. It also includes those about whom we have less knowledge acquaintances, strangers, members of our social groups or cultural communities and members of other groups. The scope and influence of our social-cognitive imaginations is arguably most apparent in these latter cases, as even young children make quick and relatively accurate inferences about people even in a first encounter. Importantly, I am not using social cognition interchangeably with "folk-psychology" or "theory of mind" (Wellman, 2014). From as early an age as they understand psychological states, children also construe people as moral agents, norm-followers, members of groups, and as having social (and intersecting) identities (Dunham et al., 2008; Gaither et al., 2020; Rakoczy \& Schmidt, 2013; Rhodes \& Chalik, 2013; Tomasello, 2019)). The social-cognitive abilities of young children include a broad range of understandings beyond their theory of mind.

The central claim of the paper is that the effectiveness of human social cognition, as well as its biases and imperfections, are all due to our ability to imagine possible alternatives to reality - our ability to think of what could have happened, what should have happened, what can happen, what must or might happen, and conversely what can't, shouldn't, mustn't, mightn't or won't. This claim is based the premise that social inference is a species of causal inference - What made this person angry? What will they do next? What's the right thing to do in this situation? Should I trust what they are telling me? In causal inference, imagination - the capacity to represent and consider what is (and isn't) possible- gives us power to explain, predict, make decisions, and learn new things, especially when faced with uncertainty, ambiguity, and incomplete information. Our social world offers some combination of uncertainty, ambiguity, and incompleteness all the time. It bears emphasis that even the most ordinary human actions are influenced by combinations of physical, biological, psychological, and social factors. All these factors could potentially matter to interpreting the meaning of an action. For instance, if my best friend is skiing 
down a big hill, her speed and trajectory (i.e., physical forces) might be as relevant to my understanding of her excitement as her love of winter sports. Physical causal knowledge can inform social judgments in some cases as much as an understanding of mental and emotional states.

We can therefore specify the role of imagination in social cognition more precisely as the ability to query our existing knowledge across domains to create, represent, and consider alternative possibilities for human actions alongside and in contrast to what we are currently experiencing. Our theory of mind, our intergroup cognition, our moral knowledge, and our knowledge of physical and biological phenomena all have some role in play to the way we predict and explain human behavior. Without this integrative, domain-general, and flexible imaginative capacity, our knowledge - our domain-specific theories - cannot be used for making social meaning.

The querying process has its own developmental timetable, one which can (and should) be an active area of investigation. At present, most of what we can conclude about developmental changes in our social-cognitive imagination is based on a literature that has presupposed its existence while ignoring its direct influence. Many tasks that are created to explore children's capacities for representing mental states and social situations require an ability to contrast current reality with representations of alternative states of the world. Tasks which are created to explore children's imaginations intermittently contain human actors as protagonists, but often are not designed to compare social events with non-social ones. Below I review some of the evidence for developmental change, even if indirect or incomplete, in the hopes that it illuminates open questions for future work.

The rest of the paper is organized as follows. In section 1 I review a work showing that even in the first year of life, infants understanding of physical causes and constraints directly influences their social judgments, all of which can be viewed through a nascent ability to imagine the physical possibilities and physical limits on action. In section 2, I discuss how imagination of what should happen is appropriately constrained by what can happen, and how this influences children's moral evaluations. In the final section, I link between developmental changes in imagination - especially the ability to imagine improbable events - to social inference, as increased imaginative capacity may lead children to appreciate that inner motives can conflict. I'll end with some ideas about how attributional biases emerge to simplify social inference in the expanding set of imagined reasons for behavior. 


\section{Crossing domains: The physics of social imagination}

Consider the following story. You are walking past an ice-cream shop and a young child is out front. She is holding a cone with a double scoop and is smiling to herself. On just this snapshot, you have certainty about a few simple facts: that the girl just came out of the shop a moment ago (the ice-cream scoops are still piled high and untouched), that she went into the shop without any ice cream in her hand but probably with a few dollars more in her pocket (ice-cream shops contain ice-cream, sell it, and give it to paying customers), and that she likes ice cream, and is happily anticipating having some. You can sense her desires, her mood, her anticipation of a goal, and therefore can predict her next move.

There is no mystery to this snapshot, or your interpretation. You are relying on your ordinary conceptual knowledge of children and their love of ice-cream, plus some understanding of ice-cream shops and how they exchange of money for food. You certainly don't even need that much backstory to infer this child's goals, beliefs, and desires - you could put aside economics, for instance, and still come to the same conclusion that she is happy in her current state. A preschool-age child would come to the same conclusion and would need no knowledge of money or shops to do so.

But what happens if, a moment later, the girl takes her eyes off the cone to look at an adorable puppy across the street and, for a split second, her hand tips slightly downwards. Now you have another snapshot - a premonition - and you cringe: at that angle, it is likely that the ice-cream will fall off the cone, leading the child to be upset, and maybe even to cry. You know all of this before you see it happen.

In this example, you (the observer) automatically recruit your knowledge of the physics of falling objects to make a mental state inference prior to observing any outcome, and critically prior to seeing any behaviors or facial expressions indicating the child is emotional or upset. You do all of this based on your ability to imagine a physical outcome and its psychological consequences. Again, a preschool-age child would do the same. Our intuitive theories of physics are implicated in psychological and social inferences all the time, from the time we have intuitive theories of objects and agents, which is to say from early in the first year of life. It is not something we necessarily notice or reflect on, but our knowledge of the physical world makes social events meaningful. 
In their classic study, Heider \& Simmel (1944; Ratajska et al., 2020) demonstrated how physical understanding informs social perception: shapes moving on a screen become meaningful social agents with interpretable goals, beliefs, desires, emotions, and relationships under certain physical conditions. Most reviews of this work focus on the autonomous movement of the shapes, as autonomous movement is a salient cue to agency, and potentially a core-cognition of agents from birth (Leslie, 1995; Spelke \& Kinzler, 2007; Xu, 2016). But mere attention to agency cues is not what makes the situation interpretable. What gives meaning to the agents' behaviors are relations between their movement and the physical obstacles in the display. Heider \& Simmel write that social inference depends critically on the "the situation" which they operationalize as shapes moving "at various speeds" and a rectangle "a section of which could be opened and closed as a door is." (p. 244). This simple display shown to participants was sufficient to elicit dramatic stories of conflict, aggression, courage, and heroism.

What do the girl with falling ice-cream and the Heider \& Simmel displays have in common? Relatedly, why do examples like this work to automatically elicit social meaning? The answer is in the way imagination queries the space of possible alternative actions and events. Our folk-physics, and how it manifests in the situations we observe, constrains the space of imagined possibilities. Children with icecream cones cannot violate physical laws, and thus we can imagine the physical consequences of the child's inattentiveness and how she may be affected by the result. The commonality with to Heider and Simmel's displays is apparent if you consider that none of the shapes are violating physical laws either. They move through doors, not through walls. When the door is closed, they are stuck inside or outside of the rectangle. Wild physical violations would have profoundly changed participants' intuitions about the characters and their relationships. One can more easily imagine triangles as agentive (and human-like) if they act like humans, which means they don't move randomly, pass through obstacles, or are nonreactive to situations involving other agents.

Studies of infants' social cognition rely on infants' intuitive physics to create social meaning. In one class of studies, infants see humans under varying degrees of freedom or physical constraint (Behne et al., 2005; Brandone \& Wellman, 2009; Gergely et al., 2002; Sommerville \& Woodward, 2005). The other class of studies comes from research that measures infants' expectations about Heider and Simmel-like displays of autonomously moving shape "agents" in the context of physical obstacles (Csibra 
et al., 1999; Gergely \& Csibra, 2003; Hamlin et al., 2007; Kuhlmeier et al., 2003). Putting aside questions as to why researchers choose one method over the other, the two methods converge on the same overall pattern of results: Infants make meaningful social-cognitive inferences - judging intentions, desires, epistemic states, moral character. Both sets of results are consistent with the idea that infants contrast what they imagine might happen and what does. Across all these studies, infants' ability to imagine alternatives depends on their knowledge of the constraints and affordances of the physical world.

Here is one example. Gergely, Bekkering, \& Király (2002) showed 14-month-old infants an actor pressing a panel with her head to turn on a light. The actor either had her hands placed on the table in front of her or she was using her hands to wrap a blanket around herself. Infants imitated the action in full - pressing the panel with their heads - when the actor's hands were free and at rest during her demonstration. In contrast, in the wrapped blanket condition, infants emulate the goal but not the means of her action, they used their hands to press the panel. The researchers argued that the behavior is based on a social inference - they encode the action as goal-directed, and evaluate the goal based on a rational principle of efficiency. The interpretation (by the authors) is that the infant's hold is the following implicit thought: If she could have achieved her goal by a more efficient means - her hands - she would have done so.

This study was designed to show that infants have expectations that agents act rationally in accordance with their intentions and goals. It also demonstrates how infants use their imaginations in social inference. A query of physical knowledge enabled infants in this study to implicitly contrast the observed action with an imagined alternative, then base their own motor plan on what they assume to be the goal of the demonstrator. Follow-up studies show when infants cannot use their own bodies to imitate the action without losing balance - for example, when the actors' hands are up above her head while she touches the panel with her head - they do not copy the whole movement (Paulus et al, 2011). These studies show that infants resist imitating actions that they cannot perform. An open question, then, is whether infants can even imagine others' actions without first gaining the relevant motor experience (see also Sommerville, Woodward \& Needham, 2005).

This ability to query physical knowledge and imagine alternative possible actions seems to be present in the first year of life. Csibra et al, (1999) habituated 9-month-old infants to a Heider-and- 
Simmel-like autonomously moving agent (a shape) jumping over a rectangular barrier to reach the other side. Looking time patterns show that infants recognize that the agent will move more efficiently, via a straight direct path, when the barrier is removed. Using the same barrier task with a human actor, Brandone \& Wellman (2009) showed that 10- to 12-month-old infants can infer a person's goals to reach for an object over a barrier even when the actor fails and that infants expect direct reaches (the most efficient path) to getting the object when the barrier is removed. This result suggests that in addition to imagining alternatives in the present, infants can imagine a future hypothetical state where a goal is achieved as well as using their physical knowledge to represent a more efficient path to achieving it.

As the above findings suggest, the physical action affordances of the immediate environment dominate infants' representations of social events. Currently some controversy exists as to whether infants can imagine alternative psychological states, such as beliefs (Buttelmann et al., 2013; Buttelmann \& Kovács, 2019; Onishi \& Baillargeon, 2005; Southgate et al., 2010; Southgate et al., 2007). It may be that infants can represent perspectives of others in simple ways, based on link between seeing something and knowing it is there (Meltzoff \& Brooks, 2008; Wellman, 2014). Luo \& Baillargeon (2007) demonstrated how this might work: They habituated 11-month-old infants to a human actor reaching for one of two objects, and the object that the actor didn't reach for was behind a barrier, which meant that she could neither reach it (physical impossibility) nor see it (epistemic impossibility). Based on equal looking times to subsequent reaches for both objects, it seems infants in this study didn't imagine the blocked object as a possible alternative goal. Unfortunately, whether this result is based on physical or epistemic limits is unclear (Kampis et al., 2013).

One interesting idea suggested by this study: it seems that infants don't consider inaction (or, put another way, intentional inhibition of action) as a viable alternative. When a person picks up the only object they see on a table, we as adults automatically interpret this action as intentional. This is based on imagining that the person could have just left the object alone, a contrast between action and inhibition, or more simply, between doing something and doing nothing. Based on Luo \& Baillargeon's (2007) results, 11-month-old infants don't do this. Additional studies (discussed below) show that it is probably not until age 5 or 6 that children think intentional inhibition is a possibility (Kushnir et al., 2015; Zhao et al., 2021). 
This limitation may also be adaptive for early social learning; the fewer possible alternatives there are for a person's behavior, the simpler it is for infants to infer its intent.

\section{Heroes and villains: Imagining what we should do in relation to what we can}

Children and adults alike enjoy stories of superheroes with extraordinary physical capabilities, like super-human strength, invisibility, gravity-defying flight, or the ability to change shape or material form. Of course, much of the fun is how superheroes defy our expectations about what is physically possible. But superheroes don't challenge our social-cognitive imaginations much; they generally have very relatable and ordinary moral qualities, such as a desire to use their powers to do good. This might be why supervillains add to the enjoyment of fantasy stories: They not only defy physics but also seem to live by

a set of guiding principles that defy ordinary morality, and often storytellers create elaborate narrative arcs to make their wickedness plausible, if not justified.

As children grow, they learn more about the causal principles that influence human actions beyond physical laws and simple psychological motives. Perhaps the most notable change is the addition of principles that govern behaviors of social groups (Birnbaum et al., 2010; Rakoczy \& Schmidt, 2013; Rhodes \& Wellman, 2017; Tomasello, 2019). A growing body of work suggests that by age three children view social and moral norms as obligatory, that is, as direct causes of action, separate from physical laws, and separate from psychological causes such as a person's own idiosyncratic desires (Kalish, 2012; Nucci, 1981). Preschool-age children seem most adamantly convinced of this fact. Using multiple methods of questioning, and in several cultures, research has consistently found that preschool-age children believe that even our most villainous desires will lose out to heroic social behavior. People who want to be mean (e.g. "(s)he wants to hit" or "(s)he wants to take all the toys for herself) will still be kind, and people who want to follow their own hearts desires will nonetheless follow parent's wishes or school rules (Chernyak et al., 2019; Chernyak \& Kushnir, 2014; Chernyak et al., 2011; Lagattuta, 2005). In fact, young children treat impermissible and immoral events as if they "cannot happen in real life" (Shtulman \& Phillips, 2018). All of this is puzzling, because we know that children appreciate a good supervillain story as much as we do. 
The suggestion here is not that children cannot entertain the possibility of villainy. Rather, that the growing understandings of the causal principles of the social world are as important to young children as their earlier understanding of the causal principles of the physical world. They are important precisely because they help children make sense of ordinary behavior in new and more sophisticated ways. It follows from this that imagining what a person should do in relation to what they can do may help children make sense of that person's behavior. The ability to do what one must, and the obligation to do what one can, separates heroes from villains, even in ordinary life.

Josephs and colleagues (2016) investigated 3- and 4-year-old children's use of imagined alternative possibilities in moral and social judgments, right at age when children start to care about rules and protest when others violate them (Rakoczy et al., 2008). In this study, children were shown a large marble run inside an opaque box with two levers at the top that connected to two exits at the bottom for marbles to pass through. Pulling one lever caused marbles to go left, and pulling two levers caused marbles to go right. Two groups of children were randomly assigned to one of two cover stories: in the social-conventional story, children were told that "the rule of the game" was to use pull both levers. In the moral story, a separate group of children were told that the marbles belonged to a friend who would be sad if they were "lost" inside the box. In this condition, the left side exit was blocked, and thus marbles could only be retrieved by pulling both levers.

Children were then introduced to a puppet named Bilbo with large enough hands to operate the device. As children observed, Bilbo either did the moral or conventionally "correct" thing (pulled both levers) or he did the "incorrect" thing (pulling one lever). The key contrast was between two types of bad action: On one of these, Bilbo was physically constrained, his hands were tied by a rope so he couldn't separate them, so it was only possible for him to pull one lever. On the other attempt, his hands were free; he could have pulled both levers, but didn't. When Bilbo behaved badly 3- and 4-year-olds alike responded with reprimands and protests, but significantly more so when the alternative action was physically possible than when he was tied and helpless. These results suggest children knew the action was wrong either way, but they understood and reacted to the bad social intentions of the puppet only when they imagined that he could have acted otherwise. 
For each new norm children learn beyond age three, imagining alternatives continues to be integral to social judgment. Zhao et al (2021) looked at how U.S. and Chinese 6-year-olds (as compared to adults) evaluate a person whose actions adhere to the following social nicety: when you don't know what other people like, it's best to leave them with options to choose from. To establish the basic effect, children and adults heard a picture-book story about two girls waiting in a snack line on two separate occasions. Behind each girl in line was another person patiently waiting their turn to get a snack. Each time a picture of the snack table displayed a single apple and two bananas. One girl took the last apple, leaving only bananas. The other girl (on the next occasion) took a banana, leaving one of each type of fruit behind. Six-year-olds and adults in both cultures thought that the girl who left one of each type of fruit was more considerate (i.e., "nicer") citing her decision to leave the next person with options to choose from as the reason.

Critically, evaluations of considerateness were not based on the outcome of the story, but on what children imagined could have happened, but didn't. To confirm this, another story told to another group of child and adult participants contrasted two girls who left the same two options - one apple and one banana - by different means. One took an apple, the other chose from three distinct fruits (orange, apple, banana) and took an orange. Though the outcome was the same, 6 -year-olds and adults judged the girl who could have acted otherwise as "nicer." One final story (for another group of participants) ended with the opposite outcome - all bananas - no options at all. Both 6-year-olds and adults evaluated as less considerate a girl who took the last apple and left only bananas, but not one who had nothing but bananas to choose from.

Imagined alternatives seem to be part of social inference from the time that a norm is meaningful to young children. In support of this idea, Zhao et al (2021) found that younger children (4- and 5-yearolds) don't differentially evaluate the two girls in any of the three stories; they don't evaluate someone as nice or not nice based on the seeing the outcome (story 1) or based on alternative outcomes that could have been (stories 2 and 3). This suggests that there is no age at which children infer social meaning from the action or its outcome without imagining the alternatives, and by extension the social intent, of the actor. 


\section{The unpredictable world of our inner desires}

So far, all the examples l've given involve causal principles - physical, psychological, social - that act in predictable ways. It would be abnormal to turn on a light switch with your forehead, to harm someone or treat them unfairly, to say you are playing a game and then proceed to break the rules. Against a background of predictability, these outcomes are not only unusual, but they are also unlikely, and it doesn't require too much imagination to think things could have turned out differently. One only needs to appeal to the "normal" way things happen (Bear \& Knobe, 2017).

Beyond the preschool years, the developing imaginations of children include a growing capacity to imagine the improbable or abnormal (Bowman-Smith et al., 2019; Goulding \& Friedman, 2021; Harris, 2021; Shtulman \& Carey, 2007; Weisberg, 2016). This fact has been documented empirically and much discussed, but to date the question of how or why the change occurs remains open. Some combination of experience, imaginative play, linguistic capacity, and executive functioning have all been suggested as potential drivers of the shift.

Regardless of how it occurs, the ability to entertain improbable, unusual, or irregular events has implications for social cognition. The most striking example is in how children change their minds about inner psychological motivations.

Initially, children's model of how desires cause actions is straightforward; if I want something, and know or believe I can have it, then all that is left to do is act to get it. This predictable relationship is a powerful tool for social learning, it makes it easy to "reverse engineer" a social inference from action back to motive (Baker et al., 2009). By the simple model that desires cause actions, all imagined alternatives will relate to features of the environment. That's how infants learn that picking one toy from two is sign of a preference (Luo \& Baillargeon, 2007; Sommerville \& Woodward, 2005, 2010). It is also how children determine when a select subset of toys from a larger set is based on wanting or liking those things (Kushnir et al., 2010). The inference gets stronger when combined with physical causal knowledge, such as when a person makes an effort to get an object out of reach rather than grabbing something close by (Jara-Ettinger et al., 2017). Something similar holds for someone who deliberately breaks rules or acts unkindly or aggressively. On a simple desire-to-action model, it's easy to judge their actions as stemming from an immoral urge or a deeper character flaw. 
At some point the simple model is replaced with a nuanced one in which inner motives are more unpredictable. For instance, 6- and 7-year-olds (but not 4-year-olds) in a recent study endorsed the possibility of emotional ambivalence- for example, being excited to ride a bike, but also being scared to do it because of a previous bike accident. Older children, but not younger ones further reported that ambivalent emotions could lead to having two conflicting desires at once (Rostad \& Pexman, 2014). In other work, 6- and 7-year-olds (but not younger children) come up with reasons why someone might not do something they really want to do, like eat "yucky" food, open a scary box, or avoid fun activities (Choe et al., 2005; Kushnir et al., 2015).

Changes in imaginative capacity - the ability to entertain possibilities that are unusual, unlikely or non-"normal" perhaps by generating them from existing conceptual knowledge - may lead to this nuanced view. Some indirect support for this claim comes from children's creative justifications for why someone might be able to do (or not do) something despite their desires (Chernyak et al., 2019; Kushnir et al., 2015; Wente et al., 2016; Zhao et al., 2021). Children's reasons cover a range of conceptual domains, they are not exclusively about desires or inner motivations. For example, when explaining why someone might not eat their favorite desert, "if she is too full" (internal biological) or "it has a lot of sugar" (external physical) are as common as "she might not want it today" (internal psychological). Some children refer to permission ("my mom won't let me") or individual differences ("some people like cereal some people don't'), introducing social reasons into the mix (Kushnir et al., 2015). In other words, at some point during middle childhood, children entertain the improbable idea of complicated and conflicting motives. Whether and how this new-found understanding rests on the ability to generate new ideas from old bits of knowledge remains an open area of investigation.

Regardless of the exact mechanism of developmental change, entertaining the possibility of complicated motives has consequences for children's developing social cognition. For one thing, children can no longer infer much from being mere observers and need to rely on other ways of learning about the social world. To this end, children lean more heavily on what they are told rather than what they see, increasingly relying on the narratives and explanations of others to frame and explain social events. Suggestively, research has documented an explosion of culture-specific narratives and culturally based 
concepts of individuals and social groups between ages 6 and 10 (Birnbaum et al., 2010; Diesendruck et al., 2013; Srinivasan et al., 2016; Wang, 2004).

Under this more expansive model of motivation, it is no longer possible to judge malicious intent just because someone did something wrong, nor is it simple to praise someone for doing good (Starmans \& Bloom, 2016; Zhao, under review). Not surprisingly, children's beliefs about whether people can and will transgress against norms become more sensitive to context (what type of norm, what reasons are given for the transgression) and culture-specific knowledge (Chernyak et al., 2019; Chernyak et al., 2013).

The final consequence of complexity is the potential for making mistakes. Attribution biases in children (Over et al., 2018; Rizzo et al., 2021), like attribution errors in adults, can result from only thinking about the most likely or available alternatives to inform interpretation (Heck et al., 2021). What counts as likely or available will depend on individual experience, and on causal principles that are most enforced by the surrounding culture.

\section{Conclusions}

Harris (2021) has argued that the most striking thing about children's imaginations is how "pedestrian" they can be. Rather than being fantastical and wild, children's alternative realities are plausible and ordinary. Here l've tried to show an advantage of this ordinariness for social cognitive development. Imagination is a domain-general capacity for recombining existing knowledge into representations of alternatives to reality. In social cognition it functions to flexibly integrate knowledge across domains pertaining to alternative causes of actions. Relatedly, the active, generative nature of imagination means that the learning child is neither helpless to innate core representations of agents and actions nor a passive recipient of cultural information. The act of imagining is integral to the social learning process itself.

Hopefully some of the ideas here ignite curiosity for future research. In adults, links have been suggested between imaginative fluency our ability to understand our social lives and identities (Gaither, 2015; Saad et al., 2012). Relatedly, we can ask more directly about the contribution of imagination to the development of new social knowledge in children, and the consequences of new ideas on the breadth of 
interpretations that children consider. Rather than exploiting children's imaginations for methodological purposes only - telling them fictional stories to find out what they know - we can encourage them to tell us stories, and ask how their imaginations change what they know (Burns, O'Connor, et al., 2021; Chernyak et al., 2017; Gaither et al., 2020). Another promising avenue of research is the link between action experience, causal knowledge, and social meaning-making. Research described above shows how infants' experience of physical agency impacts their interpretations of physical possibility. Similarly, children's experiences of psychological and moral agency might guide their understanding of social possibilities (Chernyak \& Kushnir, 2013, 2018). The experience of self-control, of not doing things you want to do, might be particularly important, as it might change children's minds about the inner world of conflicting motivations (Zhao et al., 2021).

Social cognition is error-prone, imperfect, and biased by what we already think, know, and believe about people and our social world. I've suggested that the way imagination operates on existing knowledge may lead to bias. The consequence of trying to simplify interpretation of actions is that we rely too much on the most likely or readily available alternatives. What counts as readily available depends on how social meaning is learned through our personal experience, our families, and our cultural communities.

But alongside these perhaps unfortunate consequences lives a more hopeful one. Appreciating complexity allows for the possibility of appreciating diversity; imagining other perspectives and other social meanings that radically differ from any that one has previously entertained. The same way children become more capable of imagining fantasy worlds as they get older, they may also be more capable of bridging the divide between real worlds that are familiar and ones that are totally new. Here we can again draw parallels between causal learning and social cognition: encouraging children to consider alternative possibilities beyond the most available ones can make them receptive to learning new things (Walker \& Nyhout, 2020). Similarly, imagining the many possibilities for why or how someone else's actions might be different can lead to new insights about human behavior, potentially mitigating bias.

\section{References}


Addis, D. R. (2020). Mental time travel? A neurocognitive model of event simulation. Review of Philosophy and Psychology, 11(2), 233-259. https://doi.org/10.1007/s13164-020-00470$\underline{0}$

Atance, C. M. (2015). Young children's thinking about the future. Child Development Perspectives, 9(3), 178-182. https://doi.org/10.1111/cdep.12128

Atance, C. M., Metcalf, J. L., \& Thiessen, A. J. (2017). How can we help children save? Tell them they can (if they want to). Cognitive Development, 43, 67-79. https://doi.org/10.1016/i.cogdev.2017.02.009

Baker, C. L., Saxe, R., \& Tenenbaum, J. B. (2009). Action understanding as inverse planning. Cognition, 113(3), 329-349. https://doi.org/10.1016/i.cognition.2009.07.005

Bear, A., \& Knobe, J. (2017). Normality: Part descriptive, part prescriptive. Cognition, 167, $25-$ 37. https://doi.org/10.1016/j.cognition.2016.10.024

Beck, S. R., \& Riggs, K. J. (2014). Developing thoughts about what might have been. Child Development Perspectives, 8(3), 175-179. https://doi.org/10.1111/cdep.12082

Behne, T., Carpenter, M., Call, J., \& Tomasello, M. (2005). Unwilling Versus Unable: Infants' Understanding of Intentional Action. Developmental Psychology, 41(2), 328-337. https://doi.org/10.1037/0012-1649.41.2.328

Birnbaum, D., Deeb, I., Segall, G., Ben-Eliyahu, A., \& Diesendruck, G. (2010). The development of social essentialism: The case of Israeli children's inferences about Jews and Arabs. Child Development, 81(3), 757-777. https://doi.org/10.1111/j.1467-8624.2010.01432.x

Bowman-Smith, C. K., Shtulman, A., \& Friedman, O. (2019). Distant lands make for distant possibilities: Children view improbable events as more possible in far-away locations. Developmental Psychology, 55(4), 722-728. https://doi.org/10.1037/dev0000661

Brandone, A. C., \& Wellman, H. M. (2009). You can't always get what you want: Infants understand failed goal-directed actions. Psychological Science, 20(1), 85-91. https://doi.org/10.1111/j.1467-9280.2008.02246.x

Burns, P., McCormack, T., O'Connor, P. A., Fitzpatrick, Á., \& Atance, C. (2021). The effect of episodic future thinking on young children's future-oriented decision making. Developmental Psychology, 57(6), 976-990. https://doi.org/10.1037/dev0001179

Burns, P., O'Connor, P. A., Atance, C., \& McCormack, T. (2021). More later: Delay of gratification and thought about the future in children. Child Development, 92(4), 1554-1573. https://doi.org/10.1111/cdev.13521

Buttelmann, D., Over, H., Carpenter, M., \& Tomasello, M. (2013). Eighteen-month-olds understand false beliefs in an unexpected-contents task. Journal of Experimental Child Psychology, 119. https://doi.org/10.1016/j.jecp.2013.10.002

Buttelmann, F., \& Kovács, Á. M. (2019). 14-month-olds anticipate others' actions based on their belief about an object's identity. Infancy, 24(5), 738-751. https://doi.org/10.1111/infa.12303

Chernyak, N., Kang, C., \& Kushnir, T. (2019). The cultural roots of free will beliefs: How Singaporean and US Children judge and explain possibilities for action in interpersonal contexts. Developmental Psychology, 55(4), 866.

Chernyak, N., \& Kushnir, T. (2013). Giving preschoolers choice increases sharing behavior. Psychological Science, 24(10), 1971-1979. 
Chernyak, N., \& Kushnir, T. (2014). The self as a moral agent: Preschoolers behave morally but believe in the freedom to do otherwise. Journal of Cognition and Development, 15(3), 453-464.

Chernyak, N., \& Kushnir, T. (2018). The influence of understanding and having choice on children's prosocial behavior. Current opinion in psychology, 20, 107-110.

Chernyak, N., Kushnir, T., Sullivan, K., \& Wang, Q. (2011). A Comparison of Nepalese and American Children's Concepts of Free Will. Proceedings of the Annual Meeting of the Cognitive Science Society,

Chernyak, N., Kushnir, T., Sullivan, K. M., \& Wang, Q. (2013). A Comparison of American and Nepalese Children's Concepts of Freedom of Choice and Social Constraint [https://doi.org/10.1111/cogs.12046]. Cognitive Science, 37(7), 1343-1355. https://doi.org/https://doi.org/10.1111/cogs.12046

Chernyak, N., Leech, K. A., \& Rowe, M. L. (2017). Training preschoolers' prospective abilities through conversation about the extended self. Developmental Psychology, 53(4), 652661. https://doi.org/10.1037/dev0000283

Choe, K. S., Keil, F. C., \& Bloom, P. (2005). Children's understanding of the Ulysses conflict. Developmental Science, 8(5), 387-392. https://doi.org/10.1111/j.14677687.2005.00426.x

Csibra, G., Gergely, G., Bíró, S., Koós, O., \& Brockbank, M. (1999). Goal attribution without agency cues: The perception of 'pure reason' in infancy. Cognition, 72(3), 237-267. https://doi.org/10.1016/S0010-0277(99)00039-6

De Brigard, F., Hanna, E., St Jacques, P. L., \& Schacter, D. L. (2019). How thinking about what could have been affects how we feel about what was. Cognition and Emotion, 33(4), 646-659. https://doi.org/10.1080/02699931.2018.1478280

Diesendruck, G., Goldfein-Elbaz, R., Rhodes, M., Gelman, S., \& Neumark, N. (2013). Crosscultural differences in children's beliefs about the objectivity of social categories. Child Dev, 84(6), 1906-1917. https://doi.org/10.1111/cdev.12108

Dunham, Y., Baron, A. S., \& Banaji, M. R. (2008). The development of implicit intergroup cognition. Trends Cogn Sci, 12(7), 248-253. https://doi.org/10.1016/i.tics.2008.04.006

Engle, J., \& Walker, C. M. (2021). Thinking counterfactually supports children's evidence evaluation in causal learning. Child Development, 92(4), 1636-1651. https://doi.org/10.1111/cdev.13518

Gaither, S. E. (2015). "Mixed" Results: Multiracial Research and Identity Explorations. Current Directions in Psychological Science, 24(2), 114-119. https://doi.org/10.1177/0963721414558115

Gaither, S. E., Fan, S. P., \& Kinzler, K. D. (2020). Thinking about multiple identities boosts children's flexible thinking [https://doi.org/10.1111/desc.12871]. Developmental Science, 23(1), e0012871. https://doi.org/https://doi.org/10.1111/desc.12871

Gergely, G., Bekkering, H., \& Király, I. (2002). Rational imitation in preverbal infants. Nature, 415(6873), 755-755. https://doi.org/10.1038/415755a

Gergely, G., \& Csibra, G. (2003). Teleological reasoning in infancy: The naïve theory of rational action. Trends in Cognitive Sciences, 7(7), 287-292. https://doi.org/10.1016/S13646613(03)00128-1 
Gerstenberg, T., Goodman, N. D., Lagnado, D. A., \& Tenenbaum, J. B. (2021). A counterfactual simulation model of causal judgments for physical events. Psychological Review, 128(5), 936-975. https://doi.org/10.1037/rev0000281

Gilbert, D. T., \& Wilson, T. D. (2007). Prospection: Experiencing the future. Science, 317(5843), 1351-1354. https://doi.org/10.1126/science.1144161

Goulding, B. W., \& Friedman, O. (2021). A similarity heuristic in children's possibility judgments. Child Development, 92(2), 662-671. https://doi.org/10.1111/cdev.13534

Hamlin, J. K., Wynn, K., \& Bloom, P. (2007). Social evaluation in preverbal infants. Nature, 450(7169), 557-559. https://doi.org/10.1038/nature06288

Harris, P. (2000). The Work of the Imagination (Vol. 111). Wiley-Blackwell.

Harris, P. L. (2021). Early constraints on the imagination: The realism of young children. Child Development, 92(2), 466-483. https://doi.org/10.1111/cdev.13487

Harris, P. L., German, T., \& Mills, P. (1996). Children's use of counterfactual thinking in causal reasoning. Cognition, 61, 233-259.

https://search.ebscohost.com/login.aspx?direct=true\&db=psyhref\&AN=C.FA.BCC.HARRI S.CUCTCR\&site $=$ ehost-live\&scope $=$ site

Heck, I. A., Kushnir, T., \& Kinzler, K. D. (2021). Social sampling: Children track social choices to reason about status hierarchies. J Exp Psychol Gen, 150(8), 1673-1687.

https://doi.org/10.1037/xge0001008

Heider, F., \& Simmel, M. (1944). An experimental study of apparent behavior. The American Journal of Psychology, 57, 243-259. https://doi.org/10.2307/1416950

Hitchcock, C. (2001). The Intransitivity of Causation Revealed in Equations and Graphs. The Journal of Philosophy, 98(6), 273-299. https://doi.org/10.2307/2678432

Jara-Ettinger, J., Floyd, S., Tenenbaum, J. B., \& Schulz, L. E. (2017). Children understand that agents maximize expected utilities [doi:10.1037/xge0000345]. American Psychological Association.

Josephs, M., Kushnir, T., Gräfenhain, M., \& Rakoczy, H. (2016). Children protest moral and conventional violations more when they believe actions are freely chosen. Journal of Experimental Child Psychology, 141, 247-255.

Kalish, C. W. (2012). Generalizing norms and preferences within social categories and individuals. Developmental Psychology, 48(4), 1133-1143. https://doi.org/10.1037/a0026344

Kampis, D., Somogyi, E., Itakura, S., \& Király, I. (2013). Do infants bind mental states to agents? Cognition, 129(2), 232-240. https://doi.org/10.1016/i.cognition.2013.07.004

Kominsky, J. F., Gerstenberg, T., Pelz, M., Sheskin, M., Singmann, H., Schulz, L., \& Keil, F. C. (2021). The trajectory of counterfactual simulation in development. Developmental Psychology, 57(2), 253-268. https://doi.org/10.1037/dev0001140

10.1037/dev0001140.supp (Supplemental)

Kuhlmeier, V., Wynn, K., \& Bloom, P. (2003). Attribution of dispositional states by 12-montholds. Psychological Science, 14(5), 402-408. https://doi.org/10.1111/1467-9280.01454

Kushnir, T., Gopnik, A., Chernyak, N., Seiver, E., \& Wellman, H. M. (2015). Developing intuitions about free will between ages four and six. Cognition, 138, 79-101.

Kushnir, T., Xu, F., \& Wellman, H. M. (2010). Young children use statistical sampling to infer the preferences of other people. Psychological Science, 21(8), 1134-1140. 
Lagattuta, K. H. (2005). When You Shouldn't Do What You Want to Do: Young Children's Understanding of Desires, Rules, and Emotions. Child Development, 76(3), 713-733. https://doi.org/10.1111/i.1467-8624.2005.00873.x

Leslie, A. M. (1995). A theory of agency. In D. Sperber, D. Premack, \& A. J. Premack (Eds.), Causal cognition: A multidisciplinary debate. (pp. 121-149). Clarendon Press/Oxford University Press. https://search.ebscohost.com/login.aspx?direct=true\&db=psyh\&AN=1995-98256005\&site=ehost-live\&scope=site

Luo, Y., \& Baillargeon, R. (2007). Do 125-month-old infants consider what objects others can see when interpreting their actions? Cognition, 105(3), 489-512. https://doi.org/10.1016/j.cognition.2006.10.007

McCormack, T., O'Connor, E., Cherry, J., Beck, S. R., \& Feeney, A. (2019). Experiencing regret about a choice helps children learn to delay gratification. Journal of Experimental Child Psychology, 179, 162-175. https://doi.org/10.1016/j.jecp.2018.11.005

Meltzoff, A. N., \& Brooks, R. (2008). Self-experience as a mechanism for learning about others: A training study in social cognition. Developmental Psychology, 44(5), 1257-1265. https://doi.org/10.1037/a0012888 (New Perspectives on the Effects of Action on Perceptual and Cognitive Development)

Nucci, L. P. (1981). The development of personal concepts: A domain distinct from moral or societal concepts. Child Development, 52(1), 114-121.

Nyhout, A., \& Ganea, P. A. (2019a). The development of the counterfactual imagination. Child Development Perspectives, 13(4), 254-259. https://doi.org/10.1111/cdep.12348

Nyhout, A., \& Ganea, P. A. (2019b). Mature counterfactual reasoning in 4- and 5-year-olds. Cognition, 183, 57-66. https://doi.org/10.1016/j.cognition.2018.10.027

Onishi, K. H., \& Baillargeon, R. (2005). Do 15-month-old infants understand false beliefs? Science, 308(5719), 255-258. https://doi.org/10.1126/science.1107621

Over, H., Eggleston, A., Bell, J., \& Dunham, Y. (2018). Young children seek out biased information about social groups [https://doi.org/10.1111/desc.12580]. Developmental Science, 21(3), e12580. https://doi.org/https://doi.org/10.1111/desc.12580

Piaget, J. (1952). Play, dreams and imitation in childhood. W W Norton \& Co.

Rafetseder, E., \& Perner, J. (2014). Counterfactual reasoning: Sharpening conceptual distinctions in developmental studies. Child Development Perspectives, 8(1), 54-58. https://doi.org/10.1111/cdep.12061

Rakoczy, H., \& Schmidt, M. F. H. (2013). The Early Ontogeny of Social Norms [https://doi.org/10.1111/cdep.12010]. Child Development Perspectives, 7(1), 17-21. https://doi.org/https://doi.org/10.1111/cdep.12010

Rakoczy, H., Warneken, F., \& Tomasello, M. (2008). The sources of normativity: Young children's awareness of the normative structure of games. Developmental Psychology, 44(3), 875881. https://doi.org/10.1037/0012-1649.44.3.875

10.1037/0012-1649.44.3.875.supp (Supplemental)

Ratajska, A., Brown, M. I., \& Chabris, C. F. (2020). Attributing social meaning to animated shapes: A new experimental study of apparent behavior [doi:10.5406/amerjpsyc.133.3.0295]. Univ of Illinois Press. 
Redshaw, J., Suddendorf, T., Neldner, K., Wilks, M., Tomaselli, K., Mushin, I., \& Nielsen, M. (2019). Young children from three diverse cultures spontaneously and consistently prepare for alternative future possibilities. Child Development, 90(1), 51-61. https://doi.org/10.1111/cdev.13084

Rhodes, M., \& Chalik, L. (2013). Social categories as markers of intrinsic interpersonal obligations. Psychological Science, 24(6), 999-1006. https://doi.org/10.1177/0956797612466267

Rhodes, M., \& Wellman, H. (2017). Moral learning as intuitive theory revision. Cognition, 167, 191-200. https://doi.org/10.1016/j.cognition.2016.08.013

Rizzo, M. T., Green, E. R., Dunham, Y., Bruneau, E., \& Rhodes, M. (2021). Beliefs about social norms and racial inequalities predict variation in the early development of racial bias. Developmental Science. https://doi.org/10.1111/desc.13170

Roediger lii, H. L., \& Marsh, E. J. (2003). Episodic and autobiographical memory. In Handbook of psychology: Experimental psychology, Vol. 4. (pp. 475-497). John Wiley \& Sons Inc.

Saad, C. S., Damian, R. I., Benet-Martínez, V., Moons, W. G., \& Robins, R. W. (2012). Multiculturalism and Creativity: Effects of Cultural Context, Bicultural Identity, and Ideational Fluency. Social Psychological and Personality Science, 4(3), 369-375. https://doi.org/10.1177/1948550612456560

Seligman, M. E. P., Railton, P., Baumeister, R. F., \& Sripada, C. (2013). Navigating into the future or driven by the past. Perspectives on Psychological Science, 8(2), 119-141. https://doi.org/10.1177/1745691612474317

Shtulman, A., \& Carey, S. (2007). Improbable or Impossible? How Children Reason About the Possibility of Extraordinary Events. Child Development, 78(3), 1015-1032. https://doi.org/10.1111/j.1467-8624.2007.01047.x

Shtulman, A., \& Phillips, J. (2018). Differentiating 'could' from 'should': Developmental changes in modal cognition. Journal of Experimental Child Psychology, 165, 161-182. https://doi.org/10.1016/j.jecp.2017.05.012

Sobel, D. M. (2004). Exploring the coherence of young children's explanatory abilities: Evidence from generating counterfactuals [https://doi.org/10.1348/026151004772901104]. British Journal of Developmental Psychology, 22(1), 37-58. https://doi.org/https://doi.org/10.1348/026151004772901104

Sommerville, J. A., \& Woodward, A. L. (2005). Pulling out the intentional structure of action: the relation between action processing and action production in infancy. Cognition, 95(1), 130. https://doi.org/10.1016/j.cognition.2003.12.004

Sommerville, J. A., \& Woodward, A. L. (2010). The link between action production and action processing in infancy. In F. Grammont, D. Legrand, \& P. Livet (Eds.), Naturalizing intention in action. (pp. 67-89). MIT Press. https://search.ebscohost.com/login.aspx?direct=true \&db=psyh\&AN=2009-23669004\&site=ehost-live\&scope $=$ site

Southgate, V., Chevallier, C., \& Csibra, G. (2010). Seventeen-month-olds appeal to false beliefs to interpret others' referential communication. Dev Sci, 13(6), 907-912. https://doi.org/10.1111/j.1467-7687.2009.00946.x 
Southgate, V., Senju, A., \& Csibra, G. (2007). Action anticipation through attribution of false belief by 2-year-olds. Psychological Science, 18(7), 587-592. https://doi.org/10.1111/i.1467-9280.2007.01944.x

Spelke, E. S., \& Kinzler, K. D. (2007). Core knowledge. Developmental Science, 10(1), 89-96. https://doi.org/10.1111/j.1467-7687.2007.00569.x

Srinivasan, M., Dunham, Y., Hicks, C. M., \& Barner, D. (2016). Do attitudes toward societal structure predict beliefs about free will and achievement? Evidence from the Indian caste system. Developmental Science, 19(1), 109-125. https://doi.org/10.1111/desc.12294

Starmans, C., \& Bloom, P. (2016). When the spirit is willing, but the flesh is weak: Developmental differences in judgments about inner moral conflict. Psychological Science, 27(11), 1498-1506. https://doi.org/10.1177/0956797616665813

Suddendorf, T. (2010). Episodic memory versus episodic foresight: Similarities and differences [https://doi.org/10.1002/wcs.23]. WIREs Cognitive Science, 1(1), 99-107. https://doi.org/https://doi.org/10.1002/wcs.23

Suddendorf, T., Nielsen, M., \& von Gehlen, R. (2011). Children's capacity to remember a novel problem and to secure its future solution. Developmental Science, 14(1), 26-33. https://doi.org/10.1111/j.1467-7687.2010.00950.x

Tomasello, M. (2019). The moral psychology of obligation. Behavioral and Brain Sciences, 43. https://doi.org/10.1017/S0140525X19001742

Walker, C. M., \& Gopnik, A. (2013). Causality and imagination. In M. Taylor (Ed.), The Oxford handbook of the development of imagination. (pp. 342-358). Oxford University Press. https://search.ebscohost.com/login. aspx?direct=true \&db=psyh\&AN=2013-01006022\&site=ehost-live \&scope=site

Walker, C. M., \& Nyhout, A. (2020). Asking "Why?" and "What If?": The Influence of Questions on Children's Inferences. In K. H. Corriveau, L. P. Butler, \& S. Ronfard (Eds.), The Questioning Child: Insights from Psychology and Education (pp. 252-280). Cambridge University Press. https://doi.org/DOI: 10.1017/9781108553803.013

Wang, Q. (2004). The Emergence of Cultural Self-Constructs: Autobiographical Memory and Self-Description in European American and Chinese Children. Developmental Psychology, 40(1), 3-15. https://doi.org/10.1037/0012-1649.40.1.3

Weisberg, D. S. (2016). How Fictional Worlds Are Created. Philosophy Compass, 11(8), 462-470.

Weisberg, D. S., \& Gopnik, A. (2013). Pretense, counterfactuals, and Bayesian causal models: Why what is not real really matters. Cognitive Science, 37(7), 1368-1381. https://doi.org/10.1111/cogs.12069

Wellman, H. M. (2014). Making minds: How theory of mind develops. Oxford University Press. https://search.ebscohost.com/login.aspx?direct=true \&db=psyh\&AN=2014-43850000\&site=ehost-live\&scope $=$ site

Wente, A., Ting, T., Aboody, R., Kushnir, T., \& Gopnik, A. (2016). The Relationship Between Inhibitory Control and Free Will Beliefs in 4-to 6-Year-Old-Children. CogSci,

Woodward, J., \& Hitchcock, C. (2003). Explanatory generalizations, part I: A counterfactual account. Noûs, 37(1), 1-24.

$\mathrm{Xu}, \mathrm{F}$. (2016). Preliminary thoughts on a rational constructivist approach to cognitive development: Primitives, symbols, learning, and thinking. In D. Barner \& A. S. Baron 
(Eds.), Core knowledge and conceptual change. (pp. 11-28). Oxford University Press. https://doi.org/10.1093/acprof:oso/9780190467630.003.0002

Zhao, X., Wente, A., Flecha, M. F., Galvan, D. S., Gopnik, A., \& Kushnir, T. (2021). Culture moderates the relationship between self-control ability and free will beliefs in childhood. Cognition, 210, 104609. https://doi.org/10.1016/j.cognition.2021.104609

Zhao, X. K., T. (under review). When it's not easy to do the right thing: Developmental changes in understanding cost drive evaluations of moral praiseworthiness. 